\title{
Chronic obstructive pulmonary disease in non-smokers: role of oxidative stress
}

\author{
Zainab H. Saeed ${ }^{1 *}$, Mohamed A. E. Abd El Hakim² and Nezar R. Mohamed ${ }^{1}$
}

\begin{abstract}
Background: A striking feature of chronic obstructive pulmonary disease (COPD) is its inability to resolve after cigarette smoke exposure has ended, which has contributed to the possibility that the disease could also be driven by other endogenous causes, such as autoimmunity or chronic infection. The objective of this research was to examine oxidative stress in non-smoker and ex-smoker COPD subjects and its relationship to pulmonary functions and sputum cytology.

Results: This case control-study enrolled 40 patients with COPD who are non-smokers or ex-smokers and 30 healthy controls of non-smokers or ex-smokers; oxidative stress markers, superoxide dismutase (SOD), and malondialdehyde (MDA) were compared in the two groups. All oxidative stress markers are elevated in the COPD group versus the control group. MDA has a negative correlation with FEV1and dyspnea grade.

Conclusion: Blood concentrations of SOD and MDA are consistently higher in patients with non-smokers or ex-smoker COPD when compared to non-smokers or ex-smoker healthy controls.
\end{abstract}

Keywords: COPD, Oxidative stress, Superoxide dismutase, Malondialdehyde

\section{Background}

The restriction of airflow is typically progressive and associated with an improved chronic inflammatory response to harmful particles or gasses of the airways and lungs [1].

Although the pathogenesis of COPD is still not fully known, the central role of oxidative stress is well founded in this respect [2].

In particular, cigarette smoke causes direct injury to airway epithelial cells, leading to the inflammation of the airway, affecting a number of cells such as neutrophils, macrophages, and lymphocytes, releasing reactive oxygen species (ROS), and, if not properly counterbalanced by antioxidant factors, causing additional harm [3].

In addition, activated phagocytic cells such as neutrophils and macrophages generate significant quantities of ROS when they are stimulated by inhaled particles or other inflammation mediators [4].

\footnotetext{
* Correspondence: Chestawya@yahoo.com

${ }^{1}$ Department of Chest, Minia University, Minya, Egypt

Full list of author information is available at the end of the article
}

COPD's striking characteristic is its inability to resolve after cigarette smoke exposure has ceased, leading to the possibility that the disease could also be motivated by other endogenous causes, such as autoimmunity or chronic infection [5].

Even in ex-smokers, oxidative stress continues, suggesting that oxidative stress often occurs endogenously.

In the lungs of COPD patients, alveolar macrophage numbers are enormously increased and are more activated compared to control subjects, releasing increased quantities of ROS in the form of superoxide anions and hydrogen peroxide $\left(\mathrm{H}_{2} \mathrm{O}_{2}\right)$ [6].

Extracellular superoxide dismutase (SOD) polymorphisms are more common in patients with COPD, and their expression in sputum is increased in patients with COPD, while narrow airways have decreased expression [7].

Malondialdehyde (MDA) also remains one of the most widely used oxidative damage indices [8].

The purpose of this research was to examine oxidative stress in non-smokers and ex-smokers of COPD subjects and its relationship to pulmonary functions and sputum cytology. 


\section{Methods}

This case-control study enrolled 40 patients with COPD who are non-smokers or ex-smokers and 30 healthy controls of non-smokers and ex-smokers picked from the Minia Cardio-Thoracic University Hospital's Chest Department outpatient clinics during the period of September 2018 to September 2019. The sample size was according to the time and criteria, and computerized simple randomization was done.

The study was single blinded; the author who measured the level of serum markers was blinded to the study. All other authors shared enrolment and assignment of participants.

The research was accepted by the Ethics Committee of the Faculty of Medicine, Minia University.

\section{Inclusion criteria}

1- Forty subjects of COPD who are non-smokers or stopped smoking for more than 6 months. Based on the Global Initiative for Chronic Obstructive Lung Disease guidelines, COPD was diagnosed [9].

2- Thirty subjects of non-smoker healthy control.

\section{Exclusion criteria}

Patients of:

(1) Acute exacerbation, at the time of the study, of COPD

(2) Any obvious abnormal lung parenchymal lesions

(3) Lung cancer

(4) Congestive heart failure

(5) Current smokers

(6) Drugs, e.g., anti-inflammatory, steroids, analgesics, insulin, antineoplastic, and antipsychotic drugs in the previous 2 weeks before the study

Both participants were exposed to the following conditions:

1- General and local study of history

2- The dyspnea grade was calculated using the dyspnea scale updated by the Medical Research Council (mMRC) [10]

3- Chest X-ray

4- Spirometry has been calculated by a spirometer (ZAN 300, Germany) [11]

5- Sputum cellular analysis [12]

I- The specimen is visually inspected to ensure that it is consistent with the microbiology laboratory acceptance criteria, e.g. mucoid, not frothy.

II- Wet smear is made to assess the number of epithelial cells and neutrophils in up to 20 low power fields and calculate the average for

assessment of sputum quality.

III- The sputum sample is diluted with the PBS solution in the ratio of $9 \mathrm{ml} \mathrm{PBS}: 1 \mathrm{ml}$ "9 parts PBS to 1 part sputum sample."

IV - The mixture is vortexed for 3-5 min.

$\mathrm{V}$ - Incubated at $37^{\circ} \mathrm{C}$ for $15 \mathrm{~min}$.

VI- Vortexed for 5 min until complete liquefaction of the sample.

VII-The WBCs in the sample is counted using the hemocytometer using $10 \mu \mathrm{m}$ of the sample and multiply the number of cells in the dilution factor, and cell viability is determined by the trypan blue exclusion method.

VIII-eishman-stained sputum smear is made to assess the type of cells and its percentage.

6- Markers of oxidative stress, superoxide dismutase (SOD), and malondialdehyde (MDA) by ELISA Kit SinoGeneClon Biotech Co., Ltd Catalog No: SG-10188.

\section{Sample preparation}

1. Serum/plasma:

(1) Observe the serum/plasma samples, centrifuge for $10 \mathrm{~min}$ at $3500 \mathrm{r} / \mathrm{m}$ if it is muddy. Collect the supernatant, and carry out the assay immediately.

(2) The supernatant is diluted into difference concentration with normal saline, and then take the pre-experiment.

Oxidative stress markers, superoxide dismutase (SOD), and malondialdehyde (MDA) were compared in the two groups

\section{Analysis of statistics}

Using the program called SPSS for Windows version 22, data entry and review were all carried out as well as the correlation, significance level at $P<0.05$, independent sample $T$ test for parametric quantitative data between the two groups, chi-square test (if less than $5 \%$ of cells were expected to count $<20 \%$ ) or Fisher exact test (if less than $5 \%$ of cells were expected to count $>20 \%$ ), and Mann-Whitney test for non-parametric quantitative data (expressed as median) between the two groups.

\section{Results}

This case-control study enrolled 40 patients with COPD who are non-smokers or ex-smokers and 30 healthy controls of non-smokers. Demographic and functional data of all groups are shown in Tables 1 and 2. Tables 3 and 4 show the sputum cellular analysis and degree of dyspnea of COPD subjects: $40 \%$ had dyspnea grade 4 , 
Table 1 Demographic data of all groups

\begin{tabular}{lllll}
\hline & & Case & Control & \\
& & $\boldsymbol{N}=\mathbf{4 0}$ & $\mathbf{P}$ value \\
\hline Age & Range & $45-76$ & $46-76$ & $60.9 \pm 7.2$ \\
& Mean $\pm S D$ & $60.2 \pm 9$ & $16(53.3 \%)$ & 0.731 \\
Sex & Male & $30(75 \%)$ & $14(46.7 \%)$ & 0.181 \\
& Female & $10(25 \%)$ & $18(60 \%)$ & 0.767 \\
Special habits & Non-smokers & $22(55 \%)$ & $12(40 \%)$ & $0(0 \%)$ \\
& Ex-smokers & $18(45 \%)$ & $0(0 \%)$ & \\
\end{tabular}

Independent samples $T$ test for parametric quantitative data between the two groups

Chi-square test and Fisher exact test for qualitative data between the two groups

* Significance level at $P$ value $<0.05$

$45 \%$ grade 3 , and $15 \%$ grade 2 . There was a positive correlation between FEV1and dyspnea grade (Table 7). All oxidative stress markers are elevated in the COPD group versus the control group (Table 5). Both SOD and MDA had no significant correlation with sputum cellularity; however, malondialdehyde had a significantly negative correlation with FEV1and dyspnea grade (Tables 6 and 7).

\section{Discussion}

COPD is one of the most important lung illnesses caused by smoking cigarettes [13].

Some studies have shown that oxidative stress is present in COPD both in the lung and systemic circulations $[14,15]$.

The role of antioxidant defense mechanisms in COPD and changes in these processes have been less disclosed, and previous studies have measured a small number of factors involved in oxidative stress and COPD [16-18].
Despite extensive studies all over the world, molecular mechanisms that underlie COPD pathways are not yet well known. So, we aimed to examine the role of oxidative stress in non-smoker and ex-smoker COPD subjects and its relationship to pulmonary functions and sputum cytology.

SOD is the only class of enzymes with action against superoxide radicals and is predominantly a cytosolic enzyme that exhibits substantially less activity in smokers and COPD subjects than in non-smokers in the bronchial epithelium of the human lung [19].

Studies have indicated that increased smoking-induced oxidative stress will result in the degradation and inactivation of SOD triggered by increased hydrogen peroxide output $[20,21]$.

Our research showed an increase in SOD in nonsmoker and ex-smoker COPD patients in favor of these previous results; this result ensures that smoking is a significant factor in initiating oxidative stress and depleting

Table 2 Pulmonary functions and arterial blood gasses of studied groups

\begin{tabular}{|c|c|c|c|c|}
\hline & & Case & Control & $P$ value \\
\hline & & $N=40$ & $N=30$ & \\
\hline FEV1 & $\begin{array}{l}\text { Range } \\
\text { Mean } \pm S D\end{array}$ & $\begin{array}{l}23-67 \\
45.8 \pm 13.9\end{array}$ & $\begin{array}{l}77-110 \\
92.7 \pm 10.1\end{array}$ & $<0.001^{*}$ \\
\hline FVC & $\begin{array}{l}\text { Range } \\
\text { Mean } \pm S D\end{array}$ & $\begin{array}{l}23-99 \\
70.5 \pm 21.1\end{array}$ & $\begin{array}{l}80-95 \\
88 \pm 4.2\end{array}$ & $<0.001 *$ \\
\hline FEV1\FVC ratio & $\begin{array}{l}\text { Range } \\
\text { Mean } \pm S D\end{array}$ & $\begin{array}{l}21-67 \\
43.8 \pm 13.5\end{array}$ & $\begin{array}{l}70-99 \\
87.7 \pm 8.7\end{array}$ & $<0.001^{*}$ \\
\hline $\mathrm{pH}$ & $\begin{array}{l}\text { Range } \\
\text { Mean } \pm S D\end{array}$ & $\begin{array}{l}7.3-7.5 \\
7.4 \pm 0.1\end{array}$ & $\begin{array}{l}7.3-7.5 \\
7.4 \pm 0.04\end{array}$ & 0.451 \\
\hline $\mathrm{pO}_{2}$ & $\begin{array}{l}\text { Range } \\
\text { Mean } \pm S D\end{array}$ & $\begin{array}{l}45-89 \\
63.2 \pm 11.6\end{array}$ & $\begin{array}{l}76-90 \\
85.7 \pm 3.6\end{array}$ & $<0.001^{*}$ \\
\hline $\mathrm{pCO}_{2}$ & $\begin{array}{l}\text { Range } \\
\text { Mean } \pm S D\end{array}$ & $\begin{array}{l}33-76 \\
52.2 \pm 12.8\end{array}$ & $\begin{array}{l}33-39 \\
35.6 \pm 2\end{array}$ & $<0.001^{*}$ \\
\hline $\mathrm{HCO}_{3}$ & $\begin{array}{l}\text { Range } \\
\text { Mean } \pm S D\end{array}$ & $\begin{array}{l}21-35 \\
29.3 \pm 4.1\end{array}$ & $\begin{array}{l}23-28 \\
25.4 \pm 1.3\end{array}$ & $<0.001^{*}$ \\
\hline $\mathrm{SO}_{2}$ & $\begin{array}{l}\text { Range } \\
\text { Mean } \pm S D\end{array}$ & $\begin{array}{l}75-93 \\
82.4 \pm 5.6\end{array}$ & $\begin{array}{l}94-98 \\
96.3 \pm 1.2\end{array}$ & $<0.001^{*}$ \\
\hline
\end{tabular}

Independent samples $T$ test for parametric quantitative data between the two groups

Mann-Whitney test for non-parametric quantitative data between the two groups

* Significance level at $P$ value $<0.05$ 
Table 3 Sputum cytology in the cases

\begin{tabular}{lll}
\hline & & Case \\
& & $\mathbf{N}=\mathbf{4 0}$ \\
\hline Total cells in sputum & Median & 5200 \\
& IQR & $1345-9920$ \\
Neutrophils & Median & 61 \\
& IQR & $41.8-92$ \\
Lymphocytes & Median & 38 \\
& IQR & $8-61$ \\
Monocytes & Median & 0 \\
& IQR & $0-0$ \\
\hline
\end{tabular}

SOD in COPD patients; on the other hand, it reflected the presence of another oxidative stress stimuli other than smoking for which the SOD level is increased.

In our study, there was also increased level of MDA in the non-smoker and ex-smoker COPD versus the control group. Smoking cigarettes contributes to the development of reactive oxygen species (ROS) capable of triggering the self-perpetuating lipid peroxidation chain reactions in the membranes [22].

Therefore, relative to non-smokers, there is an increased level of the lipid peroxidation product MDA in chronic smokers.

The elevated level of MDA in non-smokers and exsmokers in our work can provide a fact that smoking is not the only cause of oxidative stress in the COPD group. Several mechanisms link COPD and oxidative stress in non-smokers; some more than normally expressed proinflammatory genes have been shown to be a contributing factor in chronic inflammation of COPD and the most significant mechanism to promote the relationship between the two genes [23].

In our study, there was a positive but non-significant correlation between SOD and both FEV1 and dyspnea grade.

In stable non-smokers or subjects with COPD, Rahman et al. found no association between spirometric data and antioxidant system status [24].

Reasons for the lack of a significant correlation may relate to the variability in dietary antioxidant intake, which may result in different condition-based oxidative stresses. Moreover, a strongly positive association between FEV1 and SOD behaviors in the smokers' community was found in another study [25]. This modification can also contribute to either the gene expression

Table 4 Degree of dyspnea in the cases

\begin{tabular}{lll}
\hline & & Case \\
& & $\boldsymbol{N}=\mathbf{4 0}$ \\
\hline Degree of dyspnea & Grade 2 & $6(15 \%)$ \\
& Grade 3 & $18(45 \%)$ \\
& Grade 4 & $16(40 \%)$ \\
\hline
\end{tabular}

Table 5 Oxidative stress markers in studied groups

\begin{tabular}{lllll}
\hline & & Case & Control & $P$ value \\
& & $\mathbf{N = 4 0}$ & $\boldsymbol{N = 3 0}$ & \\
\hline Malondialdehyde & Median & 21.5 & 6.5 & $<\mathbf{0 . 0 0 1 *}$ \\
& IQR & $11-42.5$ & $5.5-7.5$ & \\
Superoxide dismutase & Median & 120.5 & 55 & $<\mathbf{0 . 0 0 1 *}$ \\
& IQR & $90-234$ & $40-66$ & \\
\hline
\end{tabular}

Mann-Whitney test for non-parametric quantitative data between the two groups

*Significance level at $P$ value $<0.05$

effects of cigarette smoke, such as SOD induction, or exogenous dietary antioxidants [25].

MDA was found to have a negative correlation with both FEV1 and dyspnea grade in the present study. Our study and various studies mentioned clearly prove the point that MDA is the marker which has consistently shown correlation with lung functions, namely, FEV1 and hence disease severity $[26,27]$.

We also found a positive correlation between FEV1 and dyspnea grade in the non-smoker and ex-smoker COPD group. Smoking cessation improves respiratory symptoms and bronchial hyper responsiveness and prevents accelerated decline in lung function, in all smokers, with or without chronic obstructive pulmonary disease. In chronic obstructive pulmonary disease as the case in our study, the underlying fibrosis and loss of alveolar attachments is probably irreversible, explaining why the forced expiratory volume in $1 \mathrm{~s}$ does not normalize after smoking cessation in these patients [28].

\section{Conclusions}

1- Blood concentrations of SOD and MDA are consistently higher in patients with non-smoker or ex-smoker COPD when compared to nonsmokers or ex-smoker healthy controls, suggesting that oxidative stress caused by factors other than smoking is an important feature in the pathogenesis of COPD.

Table 6 Correlation between oxidative stress biomarkers and both pulmonary functions and sputum cells

\begin{tabular}{llllll}
\hline & \multicolumn{2}{c}{ Malondialdehyde } & \multicolumn{2}{c}{ Superoxide dismutase } \\
\cline { 2 - 3 } & $\boldsymbol{r}$ & $\boldsymbol{P}$ value & & $\boldsymbol{r}$ & $\boldsymbol{P}$ value \\
\hline FEV1 & $-\mathbf{0 . 4 1 6}$ & $\mathbf{0 . 0 0 8 ^ { * }}$ & & 0.031 & 0.849 \\
$\mathbf{p O}_{2}$ & 0.052 & 0.752 & -0.175 & 0.279 \\
Total cells in sputum & -0.005 & 0.975 & 0.103 & 0.528 \\
Neutrophils & 0.218 & 0.177 & 0.174 & 0.282 \\
Lymphocytes & -0.227 & 0.158 & -0.125 & 0.442 \\
Monocytes & -0.200 & 0.217 & 0.035 & 0.830 \\
\hline
\end{tabular}

Pearson's correlation

*Significance level at $P$ value $<0.05$ 
Table 7 Correlation between oxidative stress biomarkers, FEV1 and dyspnea grade

\begin{tabular}{lll}
\hline & \multicolumn{2}{l}{ Dyspnea degree } \\
\cline { 2 - 3 } & $\boldsymbol{r}$ & $\boldsymbol{P}$ value \\
\hline FEV1 & $\mathbf{0 . 4 7 9}$ & $\mathbf{0 . 0 0 2 *}$ \\
Malondialdehyde & $\mathbf{- 0 . 5 2 2}$ & $\mathbf{0 . 0 0 1 *}$ \\
Superoxide dismutase & 0.036 & 0.827 \\
\hline
\end{tabular}

Spearman's correlation

*Significance level at $P$ value $<0.05$

2- Malondialdehyde has a negative correlation with FEV1and dyspnea grade in subjects with COPD; however, there was no significant correlation between markers of oxidative stress and sputum cellularity.

\section{Restrictions}

First, our sample size did not allow any differences to be observed. Second, the findings could be influenced by variations in the consumption of dietary antioxidants. Third, the subjects' physical activity is not taken into account.

\section{Future workup}

1- In order to discover the exact mechanism of oxidative stress in subjects with COPD and the effects of smoking, more research is needed.

2- A more detailed measurement can also benefit from assessing these factors in lung tissue.

\section{Abbreviations}

COPD: Chronic obstructive pulmonary disease; SOD: Superoxide dismutase MDA: Malondialdehyde; ROS: Reactive oxygen species; $\mathrm{H}_{2} \mathrm{O}_{2}$ : Hydrogen peroxide; mMRC: Modified Medical Research Council dyspnea scale: FVC: Forced vital capacity; FEV1: Forced expiratory volume in $1 \mathrm{~s}$

\section{Acknowledgements}

NA

\section{Authors' contributions}

ZS conceived the publication design and prepared the manuscript, NM collected the patients' data and revised the methods and results, and MA performed the statistical component. All authors have read and approved the final manuscript.

\section{Funding}

Nil

\section{Availability of data and materials Not applicable}

\section{Declarations}

Ethics approval and consent to participate

This study was approved by hospitals research ethics board of Minia University, and a written informed consent was obtained from either patients themselves or their relatives.

The study was registered in ClinicalTrials.gov; the registration number is NCT04748887.

The study adheres to the CONSORT guidelines.

Committee's reference number is not available
Consent for publication

Not applicable

\section{Competing interests}

The authors declare that they have no competing interests.

\section{Author details}

${ }^{1}$ Department of Chest, Minia University, Minya, Egypt. ${ }^{2}$ Department of Clinical Pathology, Faculty of Medicine, Minia University, Minya, Egypt.

Received: 7 January 2021 Accepted: 23 August 2021

Published online: 22 September 2021

\section{References}

1. Decramer M, Janssens W, Miravitlles M (2012) Chronic obstructive pulmonary disease. Lancet. 379(9823):1341-1351. https://doi.org/10.1016/ S0140-6736(11)60968-9

2. Kirkham PA, Barnes PJ (2013) Oxidative stress in COPD. Chest. 144(1):266273. https://doi.org/10.1378/chest.12-2664

3. Larsson K (2007) Aspects on pathophysiological mechanisms in COPD. J Intern Med. 262(3):311-340. https://doi.org/10.1111/j.1365-2796.2007.01837.x

4. Rahman I, Biswas SK, Kode A (2006) Oxidant and antioxidant balance in the airways and airway diseases. Eur J Pharmacol. 533(1-3):222-239. https://doi. org/10.1016/j.ejphar.2005.12.087

5. Barnes PJ, Burney PGJ, Silverman EK, Celli BR, Vestbo J, Wedzicha JA Wouters EFM (2015) Chronic obstructive pulmonary disease. Nature Rev Primers 1:1-21

6. Schaberg T, Klein U, Rau M, Eller J, Lode Subpopulations H (1995) of alveolar macrophages in smokers and nonsmokers: relation to the expression of CD11/CD18 molecules and superoxide anion production. Am J Respir Crit Care Med. 151(5):1551-1558. https://doi.org/10.1164/ajrccm.151.5.7735614

7. Regan EA, Mazur W, Meoni E, Toljamo T, Millar J, Vuopala K, Bowler RP, Rahman I, Nicks ME, Crapo JD, Kinnula VL (2011) Smoking and COPD increase sputum levels of extracellular superoxide dismutase Free Radic. Biol Med. 51:726-732

8. Lykkesfeldt J (2007) Malondialdehyde as biomarker of oxidative damage to lipids caused by smoking. Clin Chim Acta. 380(1-2):50-58. https://doi.org/1 0.1016/j.cca.2007.01.028

9. Global Initiative for Chronic Obstructive Lung Disease (GOLD). Global strategy for the diagnosis, management, and prevention of COPD 2016. Available from: http://www.goldcopd.org.

10. Doherty DE, Belfer MH, Brunton SA, Fromer L, Morris CM, Sander TC (2006) Chronic obstructive pulmonary disease: consensus recommendations for early diagnosis and treatment. J Family Pract 55:S1-S8

11. Miller MR, Hankinson J, Brusasco V, Burgos F, Casaburi R, Coates A et al (2005) Standardisation of spirometry. Eur Respir J 26(2):319-338. https://doi. org/10.1183/09031936.05.00034805

12. Spanevello A, Confalonieri M, Sulotto F, Romano F, Balzano G, Migliori GB, Bianchi A, Michetti G (2000) Induced sputum cellularity. Reference values and distribution in normal volunteers. Am J Respir Crit Care Med 162(3 Pt 1):1172-1174

13. Gan WQ, Man SF, Senthilselvan A, Sin DD (2004) Association between chronic obstructive pulmonary disease and systemic inflammation: a systematic review and a meta-analysis. Thorax 59(7):574-580. https://doi. org/10.1136/thx.2003.019588

14. Barnes PJ, Shapiro SD, Pauwels RA (2003) Chronic obstructive pulmonary disease: molecular and cellular mechanisms. Eur Respir J 22(4):672-688. https://doi.org/10.1183/09031936.03.00040703

15. van der Vaart H, Postma DS, Timens W, ten Hacken NH (2004) Acute effects of cigarette smoke on inflammation and oxidative stress: a review. Thorax 59(8):713-721. https://doi.org/10.1136/thx.2003.012468

16. Rahman I, MacNee W (1996) Role of oxidants/antioxidants in smokinginduced lung diseases. Free Radic Biol Med. 21(5):669-681. https://doi.org/1 0.1016/0891-5849(96)00155-4

17. Anderson D, Macnee W (2009) Targeted treatment in COPD: a multi-system approach for a multi-system disease. Int J Chron Obstruct Pulmon Dis. 4: 321-335. https://doi.org/10.2147/copd.s2999

18. Rahman I, MacNee W (1999) Lung glutathione and oxidative stress: implications in cigarette smoke-induced airway disease. Am J Physiol. 277(6):L1067-L1088. https://doi.org/10.1152/ajplung.1999.277.6.L1067 
19. Lakari E, Paakko P, Kinnula VL (1998) Manganese superoxide dismutase, but not CuZn superoxide dismutase, is highly expressed in the granulomas of pulmonary sarcoidosis and extrinsic allergic alveolitis. Am J Respir Crit Care Med 158(2):589-596. https://doi.org/10.1164/ajrccm.158.2.9711059

20. Garg N, Singh R, Dixit J, Jain A, Tewari V (2006) Levels of lipid peroxides and antioxidants in smokers and nonsmokers. J Periodont Res. 41(5):405-410. https://doi.org/10.1111/j.1600-0765.2006.00889.x

21. Agnihotri R, Pandurang P, Kamath SU (2009) Association of cigarette smoking with superoxide dismutase enzyme levels in subjects with chronic periodontitis. J Periodontol. 80(4):657-662. https://doi.org/10.1902/jop.2009. 080545

22. Pasupati P, Yegneshwar Rao Y, Farooq J et al (2009) Effect of cigarette smoking on lipids and oxidative stress biomarkers in patients with acute myocardial infarction. Res J Med Medical Sci. 4(2):151-159

23. Loukides S, Bakakos P, Kostikas K (2011) Oxidative stress in patients with COPD. Curr Drug Targets 4(12):469-477

24. Rahman I, Swarska E, Henry M, Stolk J, MacNee W (2000) Is there any relationship between plasma antioxidant capacity and lung function in smokers and in patients with chronic obstructive pulmonary disease? Thorax 55(3):189-193. https://doi.org/10.1136/thorax.55.3.189

25. Gilks CB, Price K, Wright JL, Churg A (1998) Antioxidant gene expression in rat lung after exposure to cigarette smoke. Am J Pathol 152(1):269-278

26. Montaño M, CisnerosJ R-VA, Pedraza-ChaverriJ MD, Ramos C et al (2010) Malondialdehyde and superoxide dismutase correlate with FEV(1) in patients with COPD associated with wood smoke exposure and tobacco smoking. Inhal Toxicol 22(10):868-874. https://doi.org/10.3109/08958378.201 0.491840

27. WaseemSM HMM, AhmadZ IN (2012) A study of pulmonary functions and lipid peroxidation biomarker in COPD correlation between malondialdehyde and lung functions. Biomed Res 23:66-71

28. Willemse BWM, Postma DS, Timens W, ten Hacken NHT (2004) The impact of smoking cessation on respiratory symptoms, lung function, airway hyperresponsiveness and inflammation. Eur Respir J 23(3):464-476. https:// doi.org/10.1183/09031936.04.00012704

\section{Publisher's Note}

Springer Nature remains neutral with regard to jurisdictional claims in published maps and institutional affiliations.

\section{Submit your manuscript to a SpringerOpen ${ }^{\circ}$ journal and benefit from:}

- Convenient online submission

- Rigorous peer review

- Open access: articles freely available online

- High visibility within the field

- Retaining the copyright to your article

Submit your next manuscript at $\boldsymbol{\nabla}$ springeropen.com 